\title{
Periaqueductal gray and emotions: the complexity of the problem and the light at the end of the tunnel, the magnetic resonance imaging
}

\author{
Dora Zelena ${ }^{1,2}$, Ophelie Menant ${ }^{3}$, Frederic Andersson ${ }^{4}$, Elodie Chaillou ${ }^{3}$
}

${ }^{1}$ Institute of Experimental Medicine, Hungarian Academy of Sciences, Budapest, Hungary; ${ }^{2}$ Centre for Neuroscience, Szentagothai Research Centre, Institute of Physiology, Medical School, University of Pecs, Pecs, Hungary; ${ }^{3} I N R A-C N R S-$ Universite de Tours-IFCE, UMR85, Physiologie de la Reproduction et des Comportements, Nouzilly, France; ${ }^{4}$ Universite François-Rabelais de Tours, Inserm, Imagerie et Cerveau UMR U930, Tours, France

E-mail:elodie.chaillou@inra.fr; zelena.dora@koki.mta.hu

\begin{abstract}
The periaqueductal gray (PAG) is less referred in relationship with emotions than other parts of the brain (e.g. cortex, thalamus, amygdala), most probably because of the difficulty to reach and manipulate this small and deeply lying structure. After defining how to evaluate emotions, we have reviewed the literature and summarized data of the PAG contribution to the feeling of emotions focusing on the behavioral and neurochemical considerations. In humans, emotions can be characterized by three main domains: the physiological changes, the communicative expressions, and the subjective experiences. In animals, the physiological changes can mainly be studied. Indeed, early studies have considered the PAG as an important center of the emotions-related autonomic and motoric processes. However, in vivo imaging have changed our view by highlighting the PAG as a significant player in emotions-related cognitive processes. The PAG lies on the crossroad of networks important in the regulation of emotions and therefore it should not be neglected. In vivo imaging represents a good tool for studying this structure in living organism and may reveal new information about its role beyond its importance in the neurovegetative regulation.
\end{abstract}

Key words: PAG, fear, pain, in vivo, magnetic resonance imaging

The periaqueductal gray (PAG) is a small deeply located mesencephalic brain structure, surrounding the aqueduct of Sylvius (Figure 1). It is located at the crossroads of different neural circuits regulating the autonomic functions. It is also involved in different behaviors such as social (O'Connell and Hofmann 2011), maternal (Noriuchi et al. 2008), aggressive (Gregg and Siegel 2001), and sexual ones (Holstege and Huynh 2011). PAG roles have been studied mainly by observing the neurovegetative responses to its activation or inhibition, showing its involvement in vocalizations (Jurgens 1994), micturition (Takasaki et al. 2010; Stone et al. 2011), modulation of the respiratory (Farmer et al. 2014; Faull et al. 2015), and cardiac functions (Xavier et al. 2014). These latter responses are often measured to evaluate emotions in animals (Menant et al. 2016a), serving as the first evidence for the role of the PAG in the regulation of emotions (Bandler and Shipley 1994; Bandler et al. 2000). However, the question arose whether the PAG - beside its well-known role in the neural circuit of pain - may also contribute to the emotional component of the pain (Price 2002). The use of in vivo Magnetic Resonance Imaging (MRI) methods have widened our view (Linnman and Borsook 2013) on the PAG complex involvement besides the emotional motoric response also in the emotional-cognitive processes (Mobbs et al. 2007; Wager et al. 2009; Buhle et al. 2013).

Corresponding author: Elodie Chaillou, PhD., INRA Val de Loire, UMR85 Physiologie de la Reproduction et des Comportements, F-37380 Nouzilly, France; e-mail: elodie.chaillou@inra.fr; Dora Zelena, PhD., Institute of Experimental Medicine, Hungarian Academy of Sciences, Budapest, Hungary; e-mail: zelena.dora@koki.mta.hu. 
Before examining the emotions-related literature of the PAG, we will first define what the emotions are.

\section{From the definition of emotions toward its neuronal network}

Throughout the literature, several definitions and theoretical concepts have been debated and proposed for emotions that have been described by numerous terms (Bindra 1970; Leventhal and Scherer 1987; Leventhal and Patrick-Miller 2000). Some of them have used the term emotional qualia (subjective experiences), based on the human perception and feeling (Russell and Mahrabian 1977; McNaughton 1989). Defined as a reaction to a particular event, similar emotional expression has been reported throughout species and described it as an evolutionary adaptive process (Darwin 1872). Some consider that primary and secondary emotions can be distinguished. Primary emotions, which are fear, joy, disgust, sadness, surprise, and anger, are innate and occur in the whole animal kingdom (Leventhal and Scherer 1987). Secondary emotions, which need "a level of complex, conscious reasoning" are learned and appear specifically in humans (Leventhal and Scherer 1987). Emotions can be described with their several components, which are bound and correlated with each other and specific to the emotional qualia (Dantzer 2002a; Mauss and Robinson 2009). The three main compo- nents used to define the emotions in humans include physiological changes, communicative expressions and subjective experiences, requiring cognitive processes (Figure 2) (Dantzer 2002a).

Several theories have been proposed to describe the emotional processes (from perception to emotions), which differed by the level of the cognitive process integration (Figure 3). According to the James-Lange theory, after perceiving a stimulus that somehow affects the person, disturbing physiological changes such as palpitations, shortness of breath, anxiety, etc. (also called arousal) occur (Cannon 1927). The acknowledgment of these symptoms at cortical level determines an emotional qualia (Schachter and Singer 1962). Thus, recognition of physical changes are the emotions. On the contrary, according to the Cannon-Bard theory (also known as thalamic theory of emotions) (Cannon 1927), the triggering event induces a nerve impulse, which goes directly to the thalamus, where the message divides. One part goes to cortex leading to subjective feelings, while the other part goes to the hypothalamus and triggers neurovegetative physical responses. Thus, interpretation of emotions at cortical level and bodily changes occur simultaneously (Schachter and Singer 1962). The two factors theory of emotions (also known as Schachter-Singer theory or appraisal theory) emphasize the importance of the cognitive process (Schachter and Singer 1962). More precisely, all the

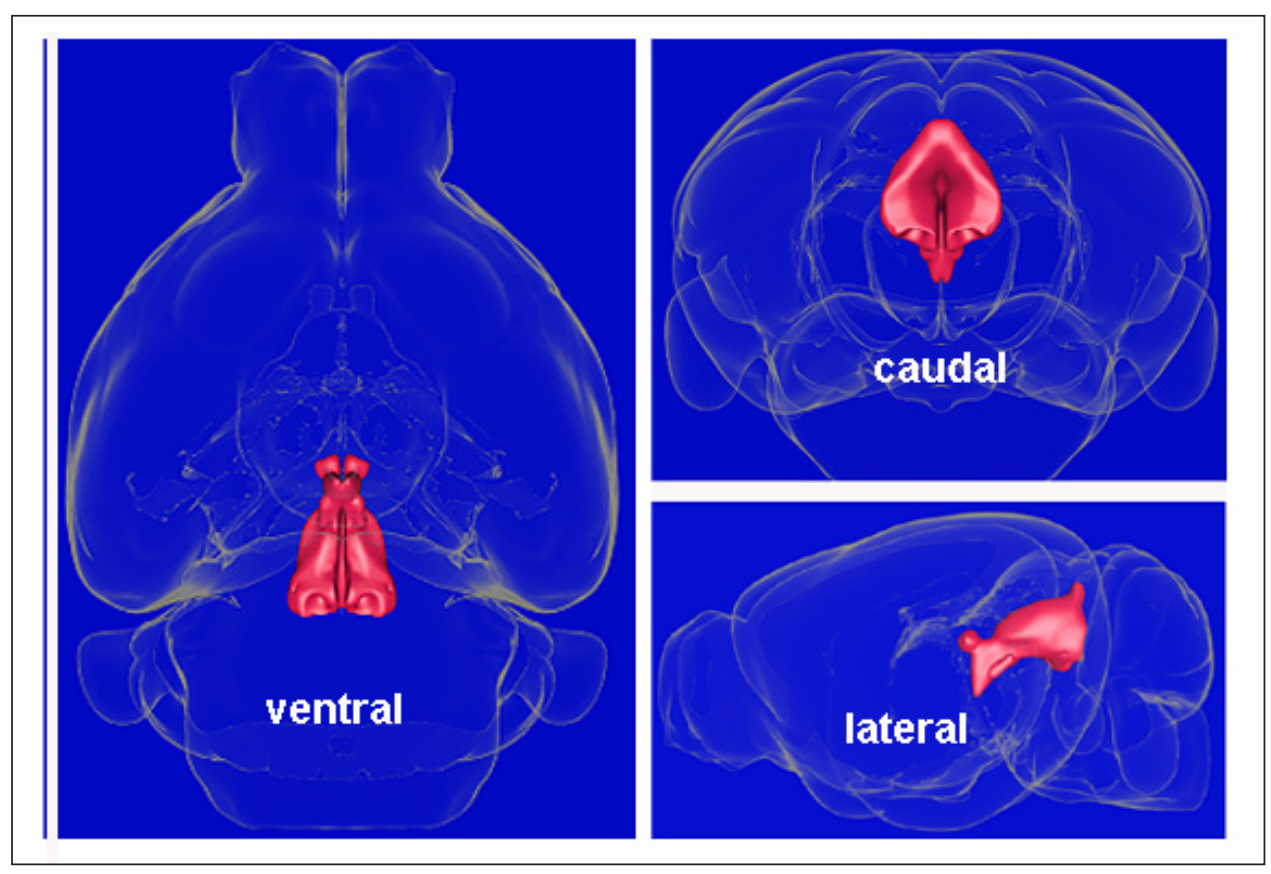

Figure 1. 3D presentations of the periaqueductal gray (PAG) in the mouse brain (red) generated with the help of https://scalablebrainatlas.incf.org/composer/. 


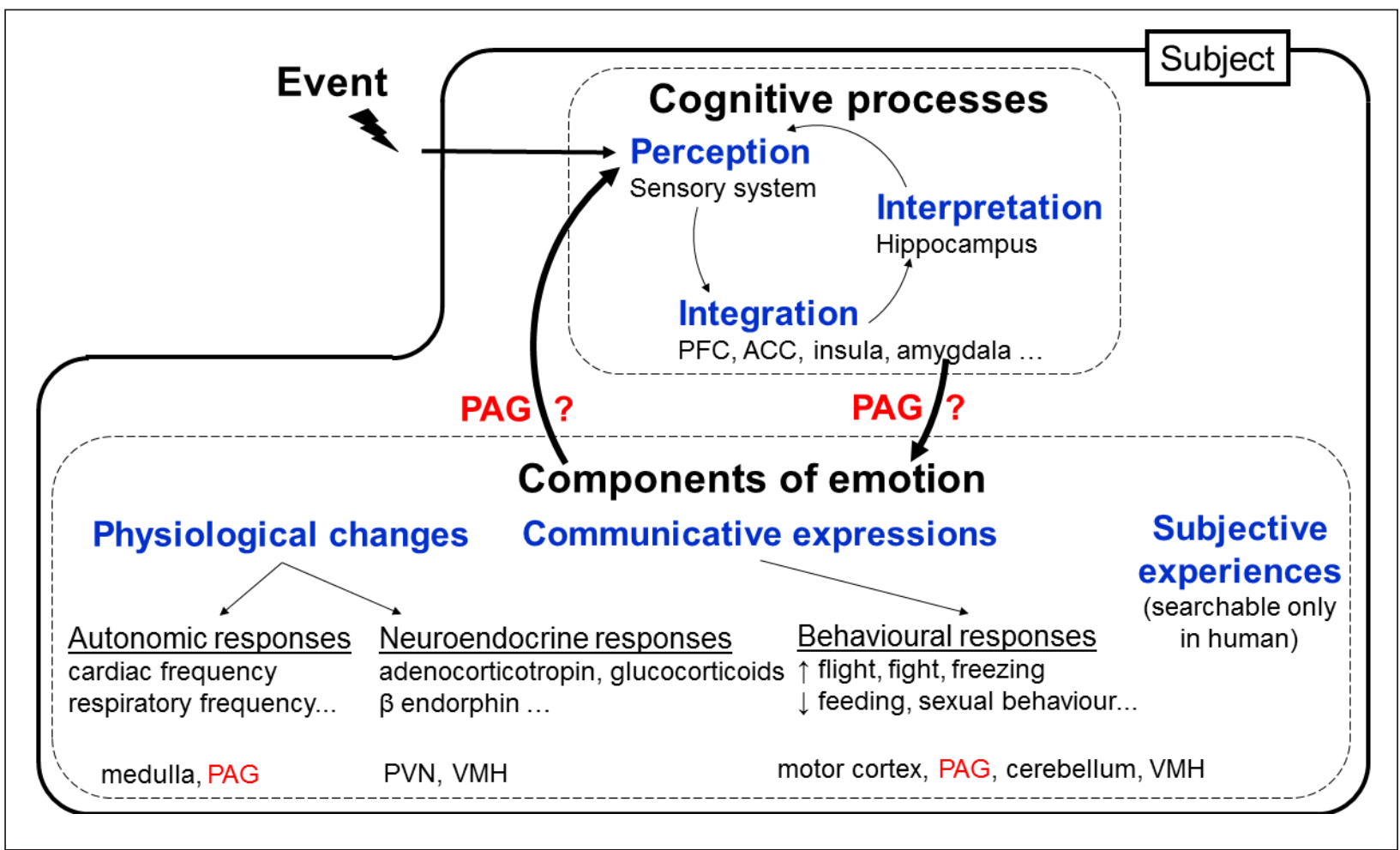

Figure 2. Schematic representation of the emotions circuit in non-human animals from the event perceived by the subject which trigger the loop of the cognitive-bodily changes. The distinct cognitive processes are mediated by specific brain structures which interact with each other and induce specific bodily changes which also influence the cognitive processes. Abbreviations: ACC anterior cingulate cortex; LH - lateral hypothalamus; PAG - periaqueductal gray; PFC - prefrontal cortex; PVN - paraventricular nucleus of the hypothalamus; VMH - ventromedial hypothalamic nucleus.

stimuli induce the same arousal and it is differentiated only by its cognitive appraisal. Based on these concepts and theories, emotions can be defined as a mental process caused by an acute event that induces intense, sudden and transient responses in our body, which appear simultaneously and have relevant aim for the organism (adapted from Kirouac 1998). The last mentioned appraisal theory integrates the three emotional components (see Figure 2) and is widely adapted in studies with non-human species (Boissy et al. 2007; Veissier and Boissy 2007). Thus, for evaluating experimentally-evoked emotions of an animal, the usual approach is to expose it to a standardized event that triggers emotions (Dantzer 2002b). Because of the lack of access to its subjective component, emotions are evaluated through physiological responses such as neurovegetative and neuroendocrine changes, behavioral responses and brain activities. For example, the exposure to a predator in nonhuman animals increases the cardiac and respiratory frequencies, enhances sympathetic activity, increases the levels of adrenocorticotropin and glucocorticoids (known as stress hormones), inhibit non-defensive behaviors (e.g. feeding behavior, sexual behavior) and induce flight or fight behavior or freezing (Apfelbach et al. 2005). These different kinds of emotional responses result from complex mental processes that could be summarized in three steps: the perception, the reaction and the cognitive control (Figure 2) under the control of the neural circuit of emotions (Menant 2016a). The perception of the particular and acute event is due to the sensory cortex such as the visual cortex (Furl 2015). The reaction is firstly due to integration and interpretation of the particular and acute event depending on the subject (age, gender, life story etc.) (Menant 2016a), which includes, for example, the prefrontal cortex (PFC), anterior cingulate cortex (ACC), insula and amygdala (Roxo et al. 2011). Then, the reaction results in autonomic and endocrine responses, under the control of the medulla (Bodnar 2012) and cerebellum (Snider and Maiti 1976), and the hypothalamic structures such as the lateral hypothalamic area $(\mathrm{LH})$ and the paraventricular $(\mathrm{PVN})$ and ventromedial (VMH) nuclei (Bodnar 2012). Fi- 


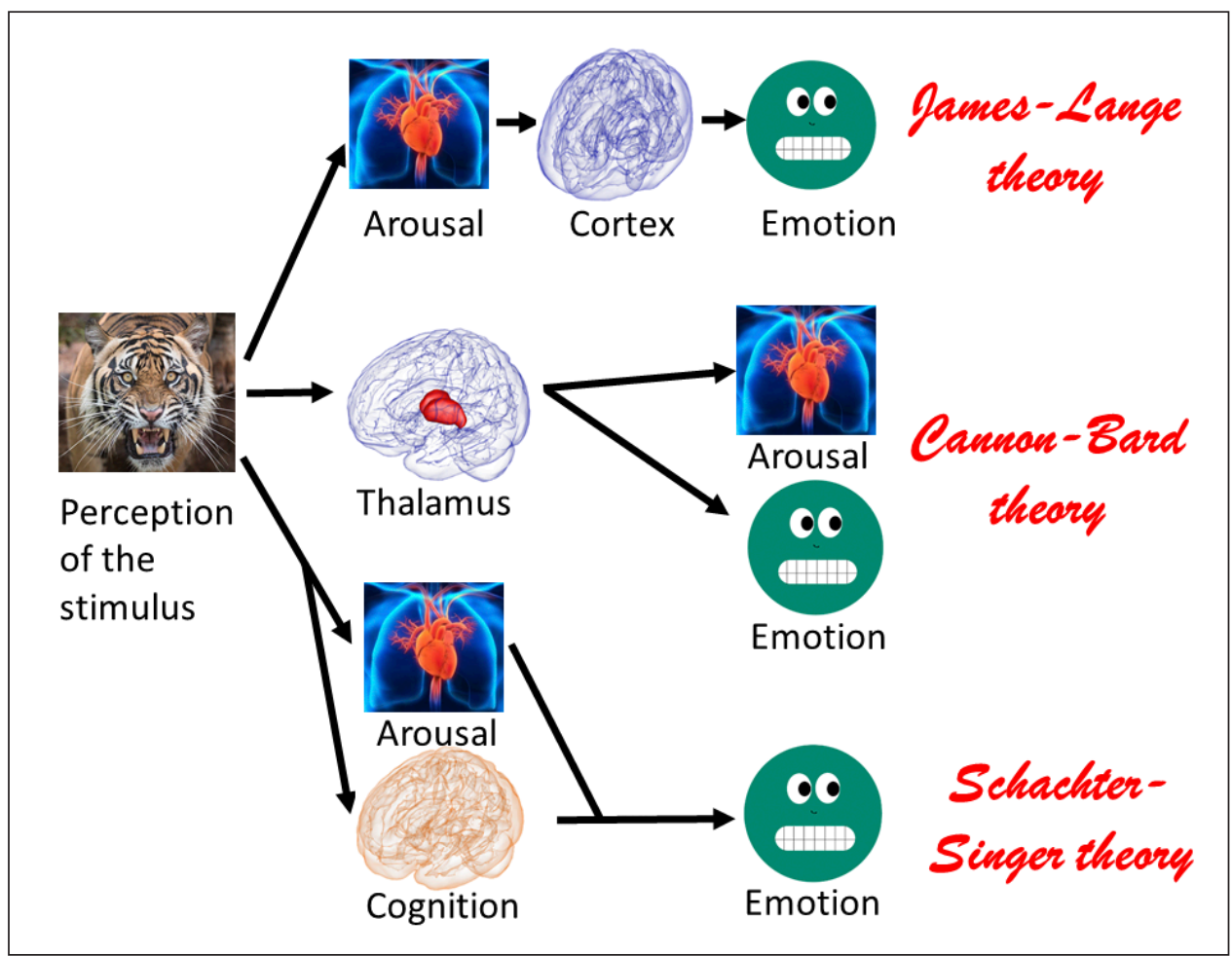

Figure 3. Comparison of the different theories for the generation of emotions. According to the James-Lange theory the perception of physical symptoms induces the feeling of different emotions at cortical level. According to the Cannon-Bard theory (also known as thalamic theory) interpretation of emotions at cortical level and physical changes occur simultaneously with the involvement of thalamus as an important relay site. The two-factor theory of emotions (also known as Schachter-Singer theory or appraisal theory) says that the feeling of emotions is the result of the perception of physical changes in our body in combination with our judgement of the situation based upon our past and present cognitive processes.

nally, the cognitive control is the step of reappraisal of the particular and acute event as well as the emotional responses, which can lead to the cessation of emotional reaction. This phase is under the control of higher brain structures such as the frontal cortex, the amygdala or the insula (Figure 2).

Examining emotions. In the experimental context, brain circuit of emotions can be studied in humans exposed to visual stimuli with different emotional valences (Paradiso et al. 1999) or in animals submitted to spontaneous acute and particular situation (Guesdon et al. 2015). It can also be studied in a conditioned situations (Phelps and LeDoux 2005). The principle is based on the fear from receiving a painful stimulus. Indeed, in fear conditioning, animals associate a conditioned stimulus (context or other neutral stimulus such as light, sound etc.) with an unconditioned stimulus (nociceptive stimulus such as footshock) to induce a conditioned response. By this way, it is possible to induce reproducible emotional responses in the animal subjected to the conditioned stimulus. Using this experimental model, different strategies have been developed to identify and study the neuronal network of emotions, which overlaps with that of pain (Garcia-Larrea and Peyron 2013). In all of these experimental approaches the PAG has been identified as a player in the neuronal network of emotions. It is even noted that it is mainly implicated in negative emotional context (fear, panic, aggressive) (Bandler and Shipley 1994; Bandler et al. 2000; Vianna and Brandao 2003). In positive emotions the role of the PAG is mainly associated with its involvement in the vocal communication in accordance with the social context (Kyuhou and Gemba 1998) and could be inferred from its involvement in specific social behaviors (Lonstein et al. 1998; Adolphs 2001; Noriuchi et al. 2008; Shepherd and Freiwald 2018).

The aim of the present article is to summarize the data supporting the role the PAG in emotions, including the nociceptive component of pain and 
its neurochemical factors. It should be noted that the role of the PAG could be reduced to stereotype responses and dependent on the descending projections to the brainstem and spinal cord (Motta et al. 2017) in accordance with its role in emotions-related motoric and neurovegetative responses. However, this point of view may need to be reevaluated based on the in vivo imaging studies describing the PAG activation in several complex cognitive processes related to emotions (Maddock et al. 2003; Noriuchi et al. 2008; Motta et al. 2017). Therefore, we aimed to pay a special attention to understand how MRI studies changed our view about the role of the PAG in emotions from being a passive executive brain area to being an active player in the appraisal.

\section{The periaqueductal gray (PAG) in emotions}

Emotions-related motoric and neurovegetative responses to PAG manipulations. First evidence of the motoric role of the midbrain area including the PAG has been described in cats by lesions altering the facio-vocal activity (Kelly et al. 1946), inducing mutism (Skultety 1958; Adametz and O'Leary 1959; Randall 1964) and increasing the hunting postures (Randall 1964). In another study, stimulation of the PAG decreased the blood pressure, induced bradycardia, and panting followed by apnoea in monkeys and cats (Turner 1954). In humans, studies have shown that the PAG stimulation could induce several physiological responses and subjective negatives experiences such as diffuse pain, the urge to urinate, fear (Nashold and Slaughter 1969), nausea, fright, piloerection (Hosobuchi 1987), distress, anxiety, and weeping (Tasker 1982), and feelings of apprehension (Young et al. 1985).

All the authors concluded that the variation of responses depended on the size and localization of the lesion or stimulation site inside the PAG. This observation is supported by complex anatomical and functional organization of this structure reported in several species (Menant et al. 2016b) and was the basic promise of the role of the PAG in coping style (Bandler and Shipley 1994; Bandler et al. 2000; Dampney 2018).

The PAG and negative emotions. The involvement of the PAG in negative emotions has been described in numerous reviews in relationship with functional effects (Bandler et al. 2000; Keay and Bandler 2002; Benarroch 2012) or neuroanatomical organization (Menant 2016a) and will be rapidly overviewed in this part in correlation with the PAG subdivisions
(Figure 4, middle part). Tachography studies using MRI supported the presence of four subdivisions in the human PAG similarly to the findings in animals (Ezra et al. 2015). The development of imaging techniques makes identification of functional subregion easier and lead to the conclusion that each subregion of the PAG may, both in human and non-human subjects, participate in distinct functional circuitry (Satpute et al. 2013).

In the dorsal part of the PAG (dPAG, including the dorsal and dorsolateral subdivisions), injections of excitatory amino acids (EAA), as the main stimulatory neurotransmitter, increased locomotion in rats (Morgan et al. 1998) and escape behavior in cats (Zhang et al. 1990) or decreased the tonic immobility duration in guinea pigs (Coutinho and Menescal-deOliveira 2010) (Figure 4, left side). This stimulation also induced deep and rapid breathing in cats (Subramanian et al. 2008), or modifications in some autonomic responses like decrease of the temperature in body extremities of rats (de Menezes et al. 2006). However, injection of EAA or deep brain stimulation in the dPAG had no effect on the mean arterial pressure in rats (de Menezes et al. 2006) and on the heart rate in humans (Pereira et al. 2010). As a summary, activation of the dPAG is sufficient to induce emotions-related autonomic and behavioral responses, however, the necessity of these subdivisions are not that clear. Indeed, although stimulation of the dPAG decreased the tonic immobility duration in guinea pigs (Coutinho and Menescal-de-Oliveira 2010) the lesion of this area did not modify the expression of freezing behavior in fear conditioned rats (Leman et al. 2003). Moreover, although the dPAG lesion decreased the basal blood pressure (Schenberg et al. 1995; Sampaio et al. 1999), its stimulation had no effect on the arterial pressure (de Menezes et al. 2006).

In the ventral part of the PAG (vPAG; including the lateral and ventrolateral subdivisions), stimulation and lesion induced opposite fear reactions. In more details, injections of EAA increased immobility in cats (Zhang et al. 1990), guinea pigs (Monassi et al. 1999; Coutinho and Menescal-de-Oliveira 2010) and rats (Morgan et al. 1998; Morgan and Carrive 2001), and lesions of the vPAG decreased freezing behaviour in rats exposed to a cat (De Oca et al. 1998) (Figure 4, left side). These results confirmed the sufficient and necessary involvement of the vPAG in fear responses. Moreover, injections of EAA in the vPAG induced abnormal pattern of breathing (apnoea), thought to be associated with emotions-related vocalizations in cats such as mew and hisses (Subramanian et al. 2008). This stimulation also modulated heart rate in 


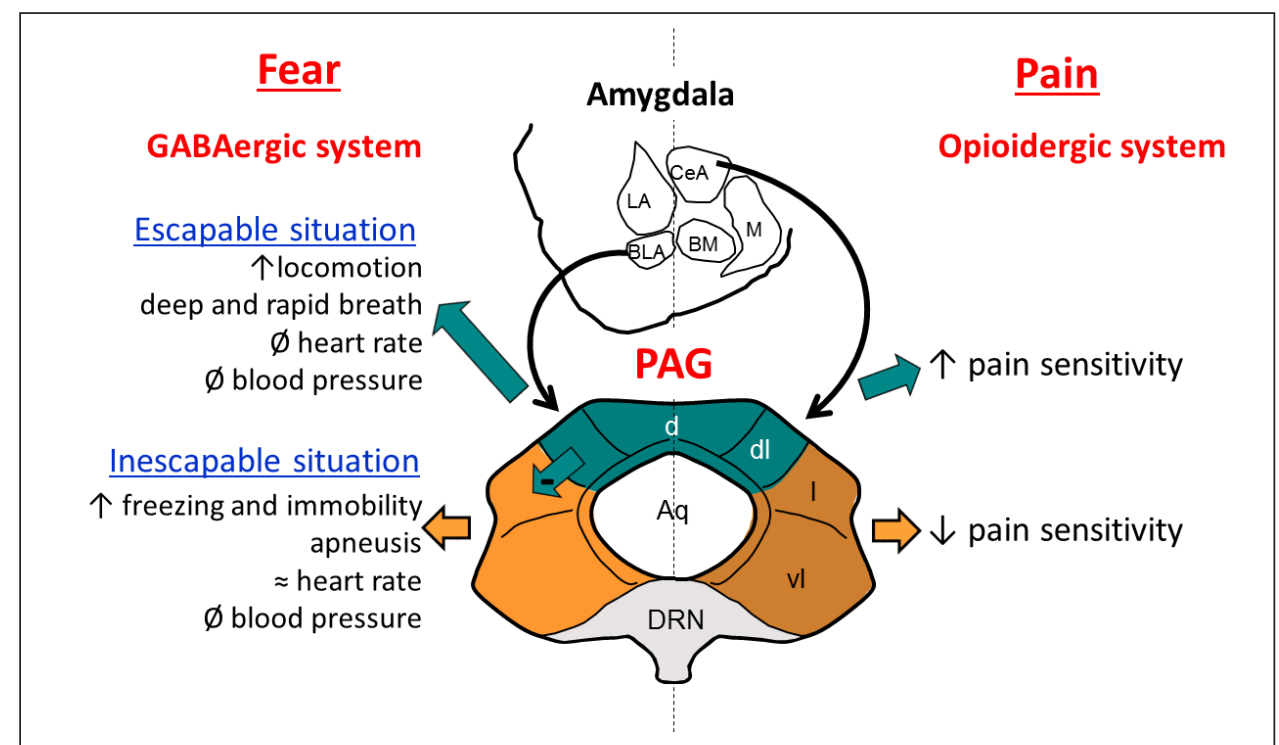

Figure 4. Schematic representation of the responses induced by the stimulation of the periaqueductal gray (PAG) subdivisions and its functional connections with the amygdala nucleus in fear and pain based upon rat brain. Some fear responses induced by the PAG is mediate by the GABAergic system from the basolateral nucleus of the amygdala, whereas some pain responses induced by the PAG is mediate by the opioidergic system from the central amygdalar nucleus. Abbreviations: Aq - Aqueduc of Sylvius; BLA - basolateral amygdalar nucleus; BM - basomedial amygdalar nucleus; CeA - central amygdalar nucleus; LA - lateral amygdalar nucleus; $\mathrm{M}$ - medial amygdalar nucleus; $\mathrm{d}$ - dorsal PAG; l - lateral PAG; dl - dorsolateral PAG; vl - ventrolateral PAG; DRN - dorsal raphe nucleus.

humans (Pereira et al. 2010) and rats (Morgan and Carrive 2001; Walker and Carrive 2003) without modifications of the mean blood pressure (Morgan and Carrive 2001).

The importance of the neuronal connections between the different subdivisions of the PAG has also been studied in fear. Although lesion of the ventral parts decreased the duration of freezing in fear conditioned test (De Oca et al. 1998), it did not influence the triggering and duration of the freezing behavior, respectively, after electrical and chemical (gammaaminobutyric acid (GABA) receptor antagonist) stimulation of the dPAG (Vianna et al. 2001). This result suggests that - despite existing anatomical connections (Jansen et al. 1998) - the vPAG does not influence the freezing behavior regulated by the dorsal parts. However, lesion of the dorsal parts increased the duration of the freezing in fear conditioned test and innate fear, suggesting that this part could inhibit the freezing behaviors through controlling the ventral parts (De Oca et al. 1998).

For studying the activation of specific PAG subdivisions, the technique of c-Fos (an immediate early gene, whose presence indicates cellular activation) immunochemistry was also used. Activation of the PAG during the fear conditioning supported its in- volvement in negative feelings. Later freezing behavior in a previously fear associated context requires learning and memory. In this regard, the re-exposure of the rats to the context, where footshock was previously applied, induced c-Fos expression in their PAG, more precisely in the vPAG (Carrive et al. 1997), providing some support for the involvement of the PAG in emotions-related cognitive processes. Moreover, in fear conditioning test, rats expressed less freezing behaviors when they were lesioned in the vPAG after or before the training period (De Oca et al. 1998). Because the vPAG-lesioned rats are more sensitive to pain (Figure 4) and able to express freezing behavior in fear situations (exposition to a cat or to a new environment) (De Oca et al. 1998), the vPAG might be necessary for retrieval during learned fear. That is not the case for the dPAG, as rats lesioned in the dPAG before the training period expressed more freezing in the footshock associated context, but also when they were exposed to a cat (De Oca et al. 1998). Thus, the dPAG could regulate fear during innate negative events and not during memory recall. The different subdivisions of the PAG participate in different neuronal circuits supported by their specific anatomical connections with the rest of the brain (Menant 2016a), which can differ between species (Menant et al. 2018). 
Altogether, activation of the dPAG induces active responses, whereas the vPAG is responsible for immobility (Figure 4). As proposed by Bandler and co-workers (Bandler and Shipley 1994; Bandler et al. 2000; Benarroch 2012) the dPAG induces active coping strategies associated to escapable context and the vPAG is responsible for the passive coping strategies associated to unescapable context.

The PAG and pain. Emotions and pain are closely linked. Indeed, "pain contains emotional feelings" and the emotional context could influence the intensity of the pain sensation (Price 2002). The PAG plays a main role in the descending pain modulatory pathway since it receives projections from cortices (cingulate and insular), amygdala and hypothalamus and modulates the ascending pain transmission through its projections to the rostral ventromedial medulla (RVM) (Basbaum and Fields 1984; Loyd and Murphy 2009). As for emotional responses, the PAG subdivisions rather than the PAG as a whole have to be studied. Indeed, in rats, lesions of the dPAG increased the pain threshold, whereas lesions of the ventral parts decreased it after tonic, muscle pain-inducing intramuscular saline injection (Lei et al. 2014). In rodents, studies showed higher c-Fos expression in the vPAG after induction of a persistent (cutaneous and deep somatic) pain than after an intermittent (cutaneous) pain event. On the contrary, c-Fos expression was higher in the dPAG after induction of an intermittent than a persistent pain (Benarroch 2012); these two events being associated to an escapable and an inescapable situation, respectively (Figure 4, right side). At first glance, the PAG implication in pain modulation could be only due to descending information to the medulla and spinal cord.

However, using electrophysiological approach, the existence of reciprocal and short-latency interactions between the PAG and the sensory thalamus was reported, which modified the pain perception in male patients treated by deep brain stimulation (Wu et al. 2014). Human MRI studies confirmed the existence of ascending projections from the PAG using probabilistic tachography (Ezra et al. 2015). The additional knowledge obtained with this method was that despite the similarities in the columnar structure of the PAG there appears to be different patterns of cortical connectivity between humans and non-human animals. We recently described specific connections between the PAG areas and the rest of the brains in sheep that was different from other mammals (Menant et al. 2018). These differences could lead to alteration in the coping style, specific for each species (prey, predator, territorial, gregarious etc.), considering the neuroethology of the cognitive function as it was proposed for friendship (Brent et al. 2014). Nevertheless, PAG subdivisions have afferent and efferent connections with PFC, cingulate cortex (Kyuhou and Gemba 1998) and amygdala (Hopkins and Holstege 1978; LeDoux et al. 1988; Oka et al. 2008), which are known to be involved in memory processes; and in an emotional context there is a correlation between the activation of all of these brain regions. This supports Schenberg's idea expressed during the symposium of the "Brazilian Society of Neuroscience and Behavior", that "in the PAG there seems to be great overlapping systems" (Blanchard et al. 2001).

Motta et al. (2017) described three distinct ascending neuronal networks from the PAG which might have a role in risk assessment, fear learning or motivational drive for appetitive seeking. In the later case the expressed behavior depended on social context, which suggest the PAG's involvement in positive emotions.

The PAG and social behavior: involvement in positive emotions? As seen in the introduction, the PAG is involved in the emission of vocalization in several animal species (Jurgens 1994), some of these vocalizations being specific to socio-emotional contexts of the behaviors (Jurgens 1994; Davis et al. 1996; Kyuhou and Gemba 1998). The involvement of the PAG in social behavior changes along the rostrocaudal axes rather than between ventral and dorsal parts (Satpute et al. 2013). For example, in guinea pigs, the electrical stimulation of the rostral part of the PAG induced "low whistle", known to be a separation call in this species, and the stimulation of the caudal part induced "purr", known to be a mating call (Kyuhou and Gemba 1998), both vocalizations associated with social contexts. In lactating rats, the electrolytic lesion of the caudal PAG modified several postures with socio-emotional behavioral consequences: decreased fear responses associated with increased attacks against male intruder; reduced sexual proceptivity and receptivity; and lead to ineffective nursing posture for milking ejection (Lonstein and Stern 1998; Lonstein et al. 1998). Using c-Fos immunohistochemistry activation of the caudal part of the PAG varied in accordance with the expression of maternal behaviors (suckling, kyphosis) (Lonstein and Stern 1997). Human electrophysiological measurements - recording differences between infant vocaland sound control-stimulation from the PAG - suggested that this structure allows rapid propagation of information with emotional valence (in this study 
from infant cues) through cortical and subcortical brain regions (Parsons et al. 2017). Because all these behavioral responses are necessary to establish social relationship with others (Levy 2002; Sebe et al. 2008; Gaudin et al. 2018), and because these social bonds are associated with positive emotional state, we suppose that the involvement of the PAG in emotions is not restricted to negative emotions.

\section{Emotions-related neurochemical composition of the PAG}

It is essential to consider the neurochemical factors insight the PAG subdivisions.

The result of the chemical stimulations suggests that the glutamatergic system mediates the freezing responses associated to the dPAG (Vianna et al. 2001).

On the other hand, local serotonin (5-HT) (Clements et al. 1985) injections into the vPAG decreased nociception (Bartsch et al. 2004), whereas injections into the dPAG decreased defensive behavior in rats (Beckett and Marsden 1997; Sela et al. 2011; Campos et al. 2013) and anxiety-like behaviors in mice (Nunes-de-Souza et al. 2011). We can assume that these specific roles of the subdivisions maybe due to different inputs from emotionally relevant brain areas such as the hypothalamic nuclei (Saavedra et al. 1974), amygdala (Asan et al. 2013; Bombardi 2014) or PFC (de Almeida et al. 2008), rather than the divergent localization of receptors seen in the case of the opioidergic system.

Indeed, the deviating role of the PAG subdivisions in regulation of pain has been supported by the divergent presence of opioids such as $\beta$-endorphin (Pesini et al. 2001) and their receptors ( $\mu$ opioid receptor) (Moskowitz and Goodman 1985; Monteillet-Agius et al. 1998; Abbadie et al. 2000). The transcutaneous electrical nerve stimulation (TENS) is known to reduce pain sensitivity through the opioidergic system. Rats have been used to study the pain threshold after induction of knee joint inflammation in combination with reversible functional activation of the dPAG or vPAG. The results showed that during TENS the pain threshold of the injured rats is similar to the control rats when the dPAG is inactivated, but is lower when the vPAG is inactivated (DeSantana et al. 2009). In line with this idea, rats, which responded less to heat stimulation, expressed more $\beta$-endorphin in the vPAG (Laprairie and Murphy 2009). These results support the notion that analgesia is mediate by the opioidergic system in the vPAG (MonteilletAgius et al. 1998; Abbadie et al. 2000; Wiedenmayer and Barr 2000) (Figure 4), that is consistent with its high $\mu$-receptor density in rats (Monteillet-Agius et al. 1998; Abbadie et al. 2000). Moreover, the opioid system of the PAG is also deeply involved in maternal behavior, since morphine injection in the rostral PAG disrupts maternal care in nulliparous rats (Moura et al. 2010), and dams exhibit different pattern of opioid receptors' expression in comparison with multiparous rats (Teodorov et al. 2011).

The GABAergic system was studied in relation with the amygdala-PAG pathway to evaluate its importance in emotions (Figure 4, left side). Injection of muscimole (GABA-A receptor agonist) in any amygdala nucleus decreased the time of freezing behavior both after electrical stimulation of the dPAG and exposure to conditioned fear test (Martinez et al. 2006). Moreover, c-Fos expression was increased in all subdivisions of the PAG after injection of muscimole in the basolateral complex of the amygdala (BLA) when the animals were fear conditioned (Rea et al. 2011). These results suggest a functional connection between the PAG and the amygdala, which has anatomical background (Rizvi et al. 1991; Oka et al. 2008; Chiou et al. 2014). This later connection seems to be specific for fear, as injection of muscimole in the BLA did not inhibit the pain response to hindpaw formalin injection (Rea et al. 2011). Although we have to mention that the amygdala-PAG pathway might be also involved in pain in some extent, as in rats, injection of formalin in the hindpaw induced c-Fos expression in both the PAG and central nucleus of the amygdala (CeA), and the electrical stimulation of the CeA increased c-Fos expression in the PAG (Nakamura et al. 2013) (Figure 4, right side). However, as the afore mentioned formalin injection induced a higher density of $\beta$-endorphin cells in the vPAG (Nakamura et al. 2013), which was associated to pain reduction (Laprairie and Murphy 2009) we might assume that the pain response may be triggered not by GABAergic, but rather opioidergic pathways.

The oxytocinergic (OT) system is present in the PAG, which contains OT-fibres (Swanson and McKellar 1979; Roeling et al. 1993) and OT-receptors (Yoshimura et al. 1993; Freeman et al. 2014). This system - specifically in the caudal PAG - is important for the anxiolytic effect of the motherhood. For example, the injection of an OT-antagonist into the caudal PAG of lactating dams increased anxiety-related behaviors and low dose of OT in stressed dams reduced their anxiety (Figueira et al. 2008). In this specific socioemotional context of the motherhood, dams have to care for their pups and express defensive behavior 
against threats like e.g. predator. In these processes the PAG subdivisions have specific, albeit opposite roles (Sukikara et al. 2010).

In conclusion, as it seems essential to consider the PAG with its anatomical and functional connections for understanding its involvement in emotions, it is also necessary to consider the neurochemical factors of the PAG with special attention to the subdivisions.

\section{Emotions and the PAG: How in vivo imaging changed our view?}

Given how we have defined the emotions and the paradigm used to study the neuronal network of emotions in animals, it is easy to understand that the subjective component of emotions cannot be studied due to the absence of verbalization in animals. Even humans are known to lie about their emotions, but at least they could be asked about their feelings. When we do this during in vivo measurements of brain activities, we can have deeper insight into the neuronal network of emotions, which cannot be obtain with any other method. The in vivo imagery also allowed to study the metabolism of brain structures using positron emission tomography (PET) scan, single photon emission computed tomography (SPECT), and magnetic resonance spectroscopy imaging (MRSI). Whereas the PET and SPECT methods required injections of radioactive tracers, MRSI does not. This makes the later method to be "unique tool to probe the biochemistry in vivo providing metabolic information non-invasively" (Osorio-Garcia et al. 2012). The development of high field strengths MRI machines and the design of the radio frequency coil improved the signal sensitivity of the MRSI method and allowed to distinguish small molecules (van der Graaf 2010) such as N-acetyl-aspartate, which is an indicator of brain pathology and pain (Baslow 2002). For example, using the $1 \mathrm{H}$ MRSI method in human, subjects with chronic daily headache had higher level of N-acetyl-aspartate-glutamate in the PAG than healthy subjects (Buonanotte et al. 2006), suggesting that the PAG could be involved in pain perception through the glutamatergic system. Animal studies may have suggested the involvement of glutamate in pain perception (Carstens et al. 1990), but for that invasive methods were necessary which might even influence the observed phenomenon. The MRSI method is the first tool, which allows the detection of neurochemical composition of a small structure like the PAG via a completely noninvasive way allowing its extensive use in human studies as well. Moreover, the in vivo imaging is the only approach that allows to study the involvement of the PAG connections in complex cognitive processes occurred in emotions, pain or social behaviors.

The PAG and negative emotions. Watching negative images (Buhle et al. 2013) or anticipating an anxious speech (Wager et al. 2009) the PAG activity was increased in humans in association with increased heart rate confirming its involvement in the emotions-related motoric processes (Wager et al. 2009). However, using functional MRI (fMRI) it has been also shown that the activity of the PAG depends on the strength of the fear-inducing situations suggesting a more complex role. In humans, distal presence of a tarantula, an escapable situation, did not activate the PAG; however, its proximal presence, a nonescapable situation, increased its activity (Mobbs et al. 2007). Whereby, the situation was more inescapable, higher was the activity of the PAG (Mobbs et al. 2007), which reflected the distance of the threat (Mobbs et al. 2010) and the probability of the negative event (Mobbs et al. 2007) judged by cognitive processes involving the PAG.

The impact of the emotional state on force control was evaluated by behavioral responses in the same time as physiological markers and brain activation. Negative emotions facilitated the force control and concluded - in accordance with results of brain activation studies - that right frontal gyrus, amygdala, and PAG are key-regions to mediate this effect (Blakemore et al. 2016). Because the PAG is activated in pain and emotional context, patients were submitted to warm stimulation (low vs. high pain) and negative emotional images (negative vs. neutral). Higher PAG activation has been observed after high vs. low pain and after watching negative vs. neutral images, suggesting the involvement of the PAG in affective processes (Buhle et al. 2013). This idea is supported by brainstem (including PAG) activation during evaluation of pleasant words compared to neutral ones confirmed by fMRI (Maddock et al. 2003).

MRI studies in humans were able to separate PAG subregions related to different emotions, similarly as it has been found with other techniques in animals (Satpute et al. 2013). Emotionally aversive images activated the lateral parts of the PAG.

The PAG and pain. Several fMRI studies have reported that physical pain induced PAG activation regardless of the location of the induction site on the body [hand (Fairhurst et al. 2012; Buhle et al. 2013), somatic or visceral (Dunckley et al. 2005)] and the 
characteristic of the stimulation [heat (Fairhurst et al. 2012; Buhle et al. 2013), electrical stimulation (Dunckley et al. 2005)].

In the aim to better understand the pain perception (La Cesa et al. 2014) and the management of pain in patients (Yu et al. 2017; Harper et al. 2018), anticipatory phenomenon and placebo effect have been studied and the PAG has been identified as an important player of these complex cognitive processes. Indeed, PAG activity increased not only when subjects received heat stimulation on their hand, but also when they were only warned and not stimulated (Fairhurst et al. 2007). Uncertainty specifically and potently increased pain, which was correlated with the activity of the PAG measured by fMRI (Yoshida et al. 2013). Thus, the PAG was activated during anticipation of a negative event (Roy et al. 2014) suggesting its involvement not only in analgesia, but also in the cognitive processes such as recalling events. The development of placebo effect would require learning and recall processes (Stewart-Williams and Podd 2004). Indeed, pain induction (thermal, shock or laser stimuli) led to placebo effect through modulation of the opioidergic-cholecystokininergic-dopaminergic pain network including the PAG (Benedetti et al. 2011). More precisely, placebo effect increased the PAG activity leading to an increased threshold of pain sensitivity, finally to less pain sensation. The PAG activity was correlated to other brain regions known to be involved in memory or pain such as the hypothalamus (Eippert et al. 2009), thalamus, ACC, insula (Wager et al. 2004; Bingel et al. 2006) and RVM (Eippert et al. 2009). Additionally, using MRI and tachography the functional connection between the above mentioned areas and the PAG was also confirmed (Ezra et al. 2015).

Altogether, in vivo imaging used in humans and interventional approaches performed in animals have demonstrated the importance of the PAG in negative affective contexts (negative emotions or pain). However, whereas animal researches demonstrated the PAG as a relay of cognitive information to the brainstem and spinal cord for stereotyped responses, in vivo imaging allowed considering the PAG as a structure involved in complex cognitive processes transmitting information to cortical levels. Interestingly, these approaches also allowed the reanalysis of the role of the PAG in the social cognition.

The PAG and social cognition. Social cognition could also be approached through examining empathy (Adolphs 2001). Empathy is conceptualized by a behavior, a personality dimension, and an experi- enced emotions concept (Reynolds and Scott 1999) and could be seen at the interface of emotions and social cognition. Empathy is essential to inhibit aggressive behavior towards others and is seen as a prosocial rather than an antisocial behavior (Decety et al. 2010). In human, children viewing other in painful situation vs. non-painful situation, activation of the whole neuronal circuit of pain including the PAG could be observed (Decety et al. 2008). In adults submitted to similar protocols, introduction of a blame game component influenced the PAG activation (Decety et al. 2010) suggesting that the level of empathy is in correlation with the PAG activation. Because the PAG is also involved in aggressive behaviors (Depaulis et al. 1989; Bandler et al. 2000), it is interesting to report another study performed by Decety et al. (2009) showing others in pain (accidental or intentional), brain activation of adolescent with aggressive conduct disorders compared with healthy controls. All the subjects showed PAG activation after viewing accidental pain vs. no pain, whereas PAG activation did not differ between accidental or intentional pain. Moreover, no difference of PAG activation has been reported between adolescent with aggressive conducted disorders and healthy controls.

Social cognition encompasses different phenomena as social perception, social recognition, social communication, and social behaviors that may involve different brain structures and neuronal networks (Adolphs 2001; Brent et al. 2014). In this context, functional neural network of social communication has been examined by fMRI in macaque monkeys showing the involvement of the PAG (Shepherd and Freiwald 2018). In humans, mothers were exposed to video of their own child (or another one) submitted to a pleasant (playing) or distress (separation) situation. The study revealed activation of the PAG in mother viewing their own child vs. other child, whatever was the context (Noriuchi et al. 2008), indicating that the PAG could be involved in social object recognition or bond attachment. These results - together with other studies on animals showing the involvement of the PAG in maternal behaviors including defense (Moura et al. 2010; Sukikara et al. 2010; Klein et al. 2014; Barba-Muller et al. 2018) - support that the PAG might be viewed as an important brain structure of the caregiving parental brain (Young et al. 2017).

\section{Conclusions}

Taken together, the PAG is a brain structure coordinating not only motoric and autonomic neurovegetative outcomes, but it seems that is also involved in 
a complex of cognitive processes. This is supported by its extensive anatomical and functional connections. The inclusion of MRI in these studies helped to change our view on the PAG that it is not only a passive executor but also an active participant in cognitive processes.

However, we should be aware of the differences between species and different animal models. Therefore, we have to consider pain, negative and positive emotions, and social cognition from an evolutionary point of view, as it has been proposed in the Research Domain Criteria (RDoC) system (Anderzhanova et al. 2017). Thus, comparison of species is of particular importance to better describe and understand the brain and its role in the cognitive functions, as it has been reviewed in more and more papers [parental brain (Bales 2017); friendship (Brent et al. 2014)]. This requires thorough knowledge of the behavior of different species using ethological approaches and to explore anatomical (Menant et al. 2018) and functional (Najafi et al. 2017) connections of different brain structures with the help of MRI and to develop postprocessing tools to get a more comprehensive picture of the various species.

\section{References}

Abbadie C, Pan YX, Pasternak GW. Differential distribution in rat brain of mu opioid receptor carboxy terminal splice variants MOR-1C-like and MOR-1-like immunoreactivity: evidence for region-specific processing. J Comp Neurol 419, 244-256, 2000.

Adametz J, O'Leary JL. Experimental mutism resulting from periaqueductal lesions in cats. Neurology 9, 636-642, 1959.

Adolphs R. The neurobiology of social cognition. Curr Opin Neurobiol 11, 231-239, 2001.

Anderzhanova E, Kirmeier T, Wotjak CT. Animal models in psychiatric research: The RDoC system as a new framework for endophenotype-oriented translational neuroscience. Neurobiol Stress 7, 47-56, 2017.

Apfelbach R, Blanchard CD, Blanchard RJ, Hayes RA, McGregor IS. The effects of predator odors in mammalian prey species: a review of field and laboratory studies. Neurosci Biobehav Rev 29, 1123-1144, 2005.

Asan E, Steinke M, Lesch KP. Serotonergic innervation of the amygdala: targets, receptors, and implications for stress and anxiety. Histochem Cell Biol 139, 785-813, 2013.

Bales KL. Parenting in Animals. Curr Opin Psychol 15, 93-98, 2017.

Bandler R, Shipley MT. Columnar organization in the midbrain periaqueductal gray: modules for emotional expression? Trends Neurosci 17, 379-389, 1994.

Bandler R, Keay KA, Floyd N, Price J. Central circuits mediating patterned autonomic activity during active vs. passive emotional coping. Brain Res Bull 53, 95-104, 2000.

Barba-Muller E, Craddock S, Carmona S, Hoekzema E. Brain plasticity in pregnancy and the postpartum period: links to maternal caregiving and mental health. Arch Womens Ment Health 2018.

Bartsch T, Knight YE, Goadsby PJ. Activation of 5-HT(1B/1D) receptor in the periaqueductal gray inhibits nociception. Ann Neurol 56, 371-381, 2004.

Basbaum AI, Fields HL. Endogenous pain control systems: brainstem spinal pathways and endorphin circuitry. Annu Rev Neurosci 7, 309-338, 1984.

Baslow MH. Evidence supporting a role for N-acetyl-L-aspartate as a molecular water pump in myelinated neurons in the central nervous system. An analytical review. Neurochem Int 40, 295-300, 2002.

Beckett S, Marsden CA. The effect of central and systemic injection of the 5-HT1A receptor agonist 8-OHDPAT and the 5-HT1A receptor antagonist WAY100635 on periaqueductal grey-induced defence behaviour. J Psychopharmacol 11, 35-40, 1997.

Benarroch EE. Periaqueductal gray: an interface for behavioral control. Neurology 78, 210-217, 2012.

Benedetti F, Carlino E, Pollo A. How placebos change the patient's brain. Neuropsychopharmacology 36, 339-354, 2011.

Bindra D. Emotion and behavior theory: current research in historical perspective. In Physiological Correlates of Emotion, Reed Elsevier. ed., Perry Black. Academic Press, USA, 1970

Bingel U, Lorenz J, Schoell E, Weiller C, Buchel C. Mechanisms of placebo analgesia: rACC recruitment of a subcortical antinociceptive network. Pain 120, 8-15, 2006.

Blakemore RL, Rieger SW, Vuilleumier P. Negative emotions facilitate isometric force through activation of prefrontal cortex and periaqueductal gray. Neuroimage 124, 627-640, 2016.

Blanchard C, Blanchard R, Fellous JM, Guimaraes FS, Irwin W, Ledoux JE, McGaugh JL, Rosen JB, Schenberg LC, Volchan E, Da Cunha C. The brain decade in debate: III. Neurobiology of emotion. Braz J Med Biol Res 34, 283-293, 2001. 
Bodnar RJ. Endogenous opiates and behavior: 2011. Peptides 38, 463-522, 2012.

Boissy A, Arnould C, Chaillou E, Desire L, Duvaux-Ponter C, Greiveldinger L, Leterrier C, Richard S, Roussel S, Saint-Dizier H, Meunier-Salaun MC, Valance D, Veissier I. Emotions and cognition: A new approach to animal welfare. Anim Welf 16, 37-43, 2007.

Bombardi C. Neuronal localization of the 5-HT2 receptor family in the amygdaloid complex. Front Pharmacol 5, 68, 2014.

Brent LJ, Chang SW, Gariepy JF, Platt ML. The neuroethology of friendship. Ann N Y Acad Sci 1316, 1-17, 2014.

Buhle JT, Kober H, Ochsner KN, Mende-Siedlecki P, Weber J, Hughes BL, Kross E, Atlas LY, McRae K, Wager TD. Common representation of pain and negative emotion in the midbrain periaqueductal gray. Soc Cogn Affect Neurosci 8, 609-616, 2013.

Buonanotte F, Schurrer C, Carpinella M, Surur A, Marangoni A, Palacio S, Forteza M, Fernandez R, Enders J. [Alteration of the antinociceptive systems in chronic daily headaches]. Rev Neurol 43, 263-267, 2006.

Campos AC, de Paula Soares V, Carvalho MC, Ferreira FR, Vicente MA, Brandao ML, Zuardi AW, Zangrossi H Jr, Guimaraes FS. Involvement of serotonin-mediated neurotransmission in the dorsal periaqueductal gray matter on cannabidiol chronic effects in panic-like responses in rats. Psychopharmacology (Berl) 226, 13-24, 2013.

Cannon WB. The James-Lange theory of emotions: A critical examination and an alternative theory. Am J Psychol 39, 106-124, 1927.

Carrive P, Leung P, Harris J, Paxinos G. Conditioned fear to context is associated with increased Fos expression in the caudal ventrolateral region of the midbrain periaqueductal gray. Neuroscience 78, 165-177, 1997.

Carstens E, Hartung M, Stelzer B, Zimmermann M. Suppression of a hind limb flexion withdrawal reflex by microinjection of glutamate or morphine into the periaqueductal gray in the rat. Pain 43, 105-112, 1990.

Chiou RJ, Kuo CC, Yen CT. Comparisons of terminal densities of cardiovascular function-related projections from the amygdala subnuclei. Auton Neurosci 181, 21-30, 2014.

Clements JR, Beitz AJ, Fletcher TF, Mullett MA. Immunocytochemical localization of serotonin in the rat periaqueductal gray: a quantitative light and electron microscopic study. J Comp Neurol 236, 60-70, 1985.

Coutinho MR, Menescal-de-Oliveira L. Role of homocysteic acid in the guinea pig (Cavia porcellus) anterior cingulate cortex in tonic immobility and the influence of NMDA receptors on the dorsal PAG. Behav Brain Res 208, 237-242, 2010.

Dampney R. Emotion and the cardiovascular system: Postulated role of inputs from the medial prefrontal cortex to the dorsolateral periaqueductal gray. Front Neurosci 12, 343, 2018.

Dantzer R. Les emotions. Presses Universitaires de France,"Que sais-je?", 2002a.

Dantzer R. Can farm animal welfare be understood without taking into account the issues of emotion and cognition? J Anim Sci 80, E1-E9, 2002b.

Darwin C. The Expression of the Emotions in Man and Animals. 1872.

Davis PJ, Zhang SP, Winkworth A, Bandler R. Neural control of vocalization: respiratory and emotional influences. J Voice 10, 23-38, 1996.

de Almeida J, Palacios JM, Mengod G. Distribution of 5-HT and DA receptors in primate prefrontal cortex: implications for pathophysiology and treatment. Prog Brain Res 172, 101-115, 2008.

Decety J, Michalska KJ, Akitsuki Y. Who caused the pain? An fMRI investigation of empathy and intentionality in children. Neuropsychologia 46, 2607-2614, 2008.

Decety J, Michalska KJ, Akitsuki Y, Lahey BB. Atypical empathic responses in adolescents with aggressive conduct disorder: a functional MRI investigation. Biol Psychol 80, 203-211, 2009.

Decety J, Echols S, Correll J. The blame game: the effect of responsibility and social stigma on empathy for pain. J Cogn Neurosci 22, 985-997, 2010.

de Menezes RC, Zaretsky DV, Fontes MA, DiMicco JA. Microinjection of muscimol into caudal periaqueductal gray lowers body temperature and attenuates increases in temperature and activity evoked from the dorsomedial hypothalamus. Brain Res 1092, 129-137, 2006.

De Oca BM, DeCola JP, Maren S, Fanselow MS. Distinct regions of the periaqueductal gray are involved in the acquisition and expression of defensive responses. J Neurosci 18, 3426-3432, 1998.

Depaulis A, Bandler R, Vergnes M. Characterization of pretentorial periaqueductal gray matter neurons mediating intraspecific defensive behaviors in the rat by microinjections of kainic acid. Brain Res 486, 121-132, 1989.

DeSantana JM, Da Silva LF, De Resende MA, Sluka KA. Transcutaneous electrical nerve stimulation at both high and low frequencies activates ventrolateral periaqueductal grey to decrease mechanical hyperalgesia in arthritic rats. Neuroscience 163, 1233-1241, 2009. 
Dunckley P, Wise RG, Fairhurst M, Hobden P, Aziz Q, Chang L, Tracey I. A comparison of visceral and somatic pain processing in the human brainstem using functional magnetic resonance imaging. J Neurosci 25, 7333-7341, 2005.

Eippert F, Bingel U, Schoell ED, Yacubian J, Klinger R, Lorenz J, Buchel C. Activation of the opioidergic descending pain control system underlies placebo analgesia. Neuron 63, 533-543, 2009.

Ezra M, Faull OK, Jbabdi S, Pattinson KT. Connectivity-based segmentation of the periaqueductal gray matter in human with brainstem optimized diffusion MRI. Hum Brain Mapp 36, 3459-3471, 2015.

Fairhurst M, Wiech K, Dunckley P, Tracey I. Anticipatory brainstem activity predicts neural processing of pain in humans. Pain 128, 101-110, 2007.

Fairhurst M, Fairhurst K, Berna C, Tracey I. An fMRI study exploring the overlap and differences between neural representations of physical and recalled pain. PLoS One 7, e48711, 2012.

Farmer DG, Bautista TG, Jones SE, Stanic D, Dutschmann M. The midbrain periaqueductal grey has no role in the generation of the respiratory motor pattern, but provides command function for the modulation of respiratory activity. Respir Physiol Neurobiol 204, 14-20, 2014.

Faull OK, Jenkinson M, Clare S, Pattinson KT. Functional subdivision of the human periaqueductal grey in respiratory control using 7 tesla fMRI. Neuroimage 113, 356-364, 2015.

Figueira RJ, Peabody MF, Lonstein JS. Oxytocin receptor activity in the ventrocaudal periaqueductal gray modulates anxiety-related behavior in postpartum rats. Behav Neurosci 122, 618-628, 2008.

Freeman SM, Walum H, Inoue K, Smith AL, Goodman MM, Bales KL, Young LJ. Neuroanatomical distribution of oxytocin and vasopressin la receptors in the socially monogamous coppery titi monkey (Callicebus cupreus). Neuroscience 273, 12-23, 2014.

Furl N. Structural and effective connectivity reveals potential network-based influences on category-sensitive visual areas. Front Hum Neurosci 9, 253, 2015.

Garcia-Larrea L, Peyron R. Pain matrices and neuropathic pain matrices: a review. Pain 154 (Suppl 1), S29-S43, 2013.

Gaudin S, Chaillou E, Wycke MA, Cornilleau F, Moussu C, Calandreau L, Laine AL, Nowak R. All bonds are not alike: A psychoendocrine evaluation of infant attachment. Dev Psychobiol 60, 90-103. 2018.

Gregg TR, Siegel A. Brain structures and neurotransmitters regulating aggression in cats: implications for human aggression. Prog Neuropsychopharmacol Biol Psychiatry. 25, 91-140, 2001.

Guesdon V, Meurisse M, Chesneau D, Picard S, Levy F, Chaillou E. Behavioral and endocrine evaluation of the stressfulness of single-pen housing compared to group-housing and social isolation conditions. Physiol Behav 147, 63-70, 2015.

Harper DE, Ichesco E, Schrepf A, Hampson JP, Clauw DJ, Schmidt-Wilcke T, Harris RE, Harte SE. Resting functional connectivity of the periaqueductal gray is associated with normal inhibition and pathological facilitation in conditioned pain modulation. J Pain 19, 635 e1-635 e15, 2018.

Holstege G, Huynh HK. Brain circuits for mating behavior in cats and brain activations and de-activations during sexual stimulation and ejaculation and orgasm in humans. Horm Behav 59, 702-707, 2011.

Hopkins DA, Holstege G. Amygdaloid projections to the mesencephalon, pons and medulla oblongata in the cat. Exp Brain Res 32, 529-547, 1978.

Hosobuchi Y. Dorsal periaqueductal gray-matter stimulation in humans. Pacing Clin Electrophysiol 10, 213-216, 1987.

Jansen AS, Farkas E, Mac Sams J, Loewy AD. Local connections between the columns of the periaqueductal gray matter: a case for intrinsic neuromodulation. Brain Res 784, 329-336, 1998.

Jurgens U. The role of the periaqueductal grey in vocal behaviour. Behav Brain Res 62, 107-117, 1994.

Keay KA, Bandler R. Distinct central representations of inescapable and escapable pain: observations and speculation. Exp Physiol 87, 275-279, 2002.

Kelly AH, Beaton LE, Magoun HW. A midbrain mechanism for facio-vocal activity. J Neurophysiol 9, 181-189, 1946.

Kirouac G. Cognition et emotions. Les presses de l'universite Laval, 223, 1998.

Klein MO, Cruz Ade M, Machado FC, Picolo G, Canteras NS, Felicio LF. Periaqueductal gray mu and kappa opioid receptors determine behavioral selection from maternal to predatory behavior in lactating rats. Behav Brain Res 274, 62-72, 2014.

Kyuhou S, Gemba H. Two vocalization-related subregions in the midbrain periaqueductal gray of the guinea pig. Neuroreport 9, 1607-1610, 1998.

La Cesa S, Tinelli E, Toschi N, Di Stefano G, Collorone S, Aceti A, Francia A, Cruccu G, Truini A, Caramia F. fMRI pain activation in the periaqueductal gray in healthy volunteers during the cold pressor test. Magn Reson Imaging 32, 236-240, 2014. 
Laprairie JL, Murphy AZ. Neonatal injury alters adult pain sensitivity by increasing opioid tone in the periaqueductal gray. Front Behav Neurosci 3, 31, 2009.

LeDoux JE, Iwata J, Cicchetti P, Reis DJ. Different projections of the central amygdaloid nucleus mediate autonomic and behavioral correlates of conditioned fear. J Neurosci 8, 2517-2529, 1988.

Lei J, Sun T, Lumb BM, You HJ. Roles of the periaqueductal gray in descending facilitatory and inhibitory controls of intramuscular hypertonic saline induced muscle nociception. Exp Neurol 257, 88-94, 2014.

Leman S, Dielenberg RA, Carrive P. Effect of dorsal periaqueductal gray lesion on cardiovascular and behavioural responses to contextual conditioned fear in rats. Behav Brain Res 143, 169-176, 2003.

Leventhal H, Scherer K. The relationship of emotion to cognition: A functional approach to a semantic controversy. Cogn Emot 1, 3-28, 1987.

Leventhal H, Patrick-Miller L. Emotions and physical illness: Causes and indicators of vulnerability. Handbook of Emotions, 2nd ed. M. Lewis \& J. M. Haviland-Jones, New York, Guilford Press, 2000.

Levy F. Neurobiological mechanisms involved in recognition of olfactory signature of the young in sheep. J Soc Biol 196, 77-83, 2002.

Linnman C, Borsook D. Completing the Pain Circuit: Recent Advances in Imaging Pain and Inflammation beyond the Central Nervous System. Rambam Maimonides Med J 4, e0026, 2013.

Lonstein JS, Stern JM. Somatosensory contributions to c-fos activation within the caudal periaqueductal gray of lactating rats: effects of perioral, rooting, and suckling stimuli from pups. Horm Behav 32, 155-166, 1997.

Lonstein JS, Stern JM. Site and behavioral specificity of periaqueductal gray lesions on postpartum sexual, maternal, and aggressive behaviors in rats. Brain Res 804, 21-35, 1998.

Lonstein JS, Simmons DA, Stern JM. Functions of the caudal periaqueductal gray in lactating rats: kyphosis, lordosis, maternal aggression, and fearfulness. Behav Neurosci 112, 1502-1518, 1998.

Loyd DR, Murphy AZ. The role of the periaqueductal gray in the modulation of pain in males and females: are the anatomy and physiology really that different? Neural Plast 2009, 462879, 2009.

Maddock RJ, Garrett AS, Buonocore MH. Posterior cingulate cortex activation by emotional words: fMRI evidence from a valence decision task. Hum Brain Mapp 18, 30-41, 2003.

Martinez RC, de Oliveira AR, Brandao ML. Conditioned and unconditioned fear organized in the periaqueductal gray are differentially sensitive to injections of muscimol into amygdaloid nuclei. Neurobiol Learn Mem 85, 58-65, 2006.

Mauss IB, Robinson MD. Measures of emotion: A review. Cogn Emot 23, 209-237, 2009.

McNaughton N. Biology and Emotion (Problems in the Behavioural Sciences). Cambridge, Cambridge University Press, 1989.

Menant O, Andersson F, Zelena D, Chaillou E. The benefits of magnetic resonance imaging methods to extend the knowledge of the anatomical organisation of the periaqueductal gray in mammals. J Chem Neuroanat 77, $110-120,2016 a$

Menant O, Destrez A, Deiss V, Boissy A, Delagrange P, Calandreau L, Chaillou E. Regulation des emotions chez l'animal d'elevage : focus sur les acteurs neurobiologiques. INRA Prod Anim 29, 241-254, $2016 \mathrm{~b}$.

Menant O, Prima MC, Morisse M, Cornilleau F, Moussu C, Gautier A, Blanchon H, Meurisse M, Delagrange P, Tillet $\mathrm{Y}$, Chaillou E. First evidence of neuronal connections between specific parts of the periaqueductal gray (PAG) and the rest of the brain in sheep: placing the sheep PAG in the circuit of emotion. Brain Struct Funct 223, 3297-3316, 2018.

Mobbs D, Petrovic P, Marchant JL, Hassabis D, Weiskopf N, Seymour B, Dolan RJ, Frith CD. When fear is near: threat imminence elicits prefrontal-periaqueductal gray shifts in humans. Science 317, 1079-1083, 2007.

Mobbs D, Yu R, Rowe JB, Eich H, FeldmanHall O, Dalgleish T. Neural activity associated with monitoring the oscillating threat value of a tarantula. Proc Natl Acad Sci U S A 107, 20582-20586, 2010.

Monassi CR, Leite-Panissi CR, Menescal-de-Oliveira L. Ventrolateral periaqueductal gray matter and the control of tonic immobility. Brain Res Bull 50, 201-218, 1999.

Monteillet-Agius G, Fein J, Anton B, Evans CJ. ORL-1 and mu opioid receptor antisera label different fibers in areas involved in pain processing. J Comp Neurol 399, 373-383, 1998.

Morgan MM, Whitney PK, Gold MS. Immobility and flight associated with antinociception produced by activation of the ventral and lateral/dorsal regions of the rat periaqueductal gray. Brain Res 804, 159-166, 1998.

Morgan MM, Carrive P. Activation of the ventrolateral periaqueductal gray reduces locomotion but not mean arterial pressure in awake, freely moving rats. Neuroscience 102, 905-910, 2001.

Moskowitz AS, Goodman RR. Autoradiographic analysis of mu1, mu2, and delta opioid binding in the central nervous system of C57BL/6BY and CXBK (opioid receptor-deficient) mice. Brain Res 360, 108-116, 1985. 
Motta SC, Carobrez AP, Canteras NS. The periaqueductal gray and primal emotional processing critical to influence complex defensive responses, fear learning and reward seeking. Neurosci Biobehav Rev 76, 39-47, 2017.

Moura LM, Canteras NS, Sukikara MH, Felicio LF. Morphine infusions into the rostrolateral periaqueductal gray affect maternal behaviors. Braz J Med Biol Res 43, 899-905, 2010.

Najafi M, Kinnison J, Pessoa L. Dynamics of Intersubject Brain Networks during Anxious Anticipation. Front Hum Neurosci 11, 552, 2017.

Nakamura T, Tomida M, Yamamoto T, Ando H, Takamata T, Kondo E, Kurasawa I, Asanuma N. The endogenous opioids related with antinociceptive effects induced by electrical stimulation into the amygdala. Open Dent J 7, 27-35, 2013.

Nashold BS Jr., Slaughter DG. Effects of stimulating or destroying the deep cerebellar regions in man. J Neurosurg 31, 172-186, 1969.

Noriuchi MY, Kikuchi Y, Senoo A. The functional neuroanatomy of maternal love: mother's response to infant's attachment behaviors. Biol Psychiatry 63, 415-423, 2008.

Nunes-de-Souza V, Nunes-de-Souza R, Rodgers RJ, Canto-de-Souza A. Blockade of 5-HT(2) receptors in the periaqueductal grey matter (PAG) abolishes the anxiolytic-like effect of 5-HT(1A) receptor antagonism in the median raphe nucleus in mice. Behav Brain Res 225, 547-553, 2011.

O'Connell LA, Hofmann HA. The vertebrate mesolimbic reward system and social behavior network: a comparative synthesis. J Comp Neurol 519, 3599-5639, 2011.

Oka T, Tsumori T, Yokota S, Yasui Y. Neuroanatomical and neurochemical organization of projections from the central amygdaloid nucleus to the nucleus retroambiguus via the periaqueductal gray in the rat. Neurosci Res 62, 286-298, 2008.

Osorio-Garcia MI, Croitor Sava AR, Sima DM, Nielsen FU, Himmelreich U, Van Huffel S. Quantification Improvements of 1H MRS Signals. In: Magnetic Resonance Spectroscopy (Ed. Dong-Hyun Kim), pp. 3-28, IntechOpen, London, 2012.

Paradiso S, Johnson DL, Andreasen NC, O’Leary DS, Watkins GL, Ponto LL, Hichwa RD. Cerebral blood flow changes associated with attribution of emotional valence to pleasant, unpleasant, and neutral visual stimuli in a PET study of normal subjects. Am J Psychiatry 156, 1618-1629, 1999.

Parsons CE, Young KS, Stein A, Kringelbach ML. Intuitive parenting: understanding the neural mechanisms of parents' adaptive responses to infants. Curr Opin Psychol 15, 40-44, 2017.

Pereira EA, Lu G, Wang S, Schweder PM, Hyam JA, Stein JF, Paterson DJ, Aziz TZ, Green AL. Ventral periaqueductal grey stimulation alters heart rate variability in humans with chronic pain. Exp Neurol 223, 574-581, 2010.

Pesini P, Pego-Reigosa R, Tramu G, Covenas R. Distribution of alpha-neoendorphin immunoreactivity in the diencephalon and the brainstem of the dog. J Chem Neuroanat 22, 251-262, 2001.

Phelps EA, LeDoux JE. Contributions of the amygdala to emotion processing: from animal models to human behavior. Neuron 48, 175-187, 2005.

Price DD. Central neural mechanisms that interrelate sensory and affective dimensions of pain. Mol Interv 2, 392403, 339, 2002.

Randall WL. The behavior of cats (Felis catus L.) with lesions in the caudal midbrain region. Behaviour 23, 107-134, 1964.

Rea K, Roche M, Finn DP. Modulation of conditioned fear, fear-conditioned analgesia, and brain regional c-Fos expression following administration of muscimol into the rat basolateral amygdala. J Pain 12, 712-721, 2011.

Reynolds WJ, Scott B. Empathy: a crucial component of the helping relationship. J Psychiatr Ment Health Nurs 6, 363-370, 1999

Rizvi TA, Ennis M, Behbehani MM, Shipley MT. Connections between the central nucleus of the amygdala and the midbrain periaqueductal gray: topography and reciprocity. J Comp Neurol 303, 121-131, 1991.

Roeling TA, Veening JG, Peters JP, Vermelis ME, Nieuwenhuys R. Efferent connections of the hypothalamic "grooming area" in the rat. Neuroscience 56, 199-225, 1993.

Roxo MR, Franceschini PR, Zubaran C, Kleber FD, Sander JW. The limbic system conception and its historical evolution. ScientificWorldJournal 11, 2428-2441, 2011.

Roy M, Shohamy D, Daw N, Jepma M, Wimmer GE, Wager TD. Representation of aversive prediction errors in the human periaqueductal gray. Nat Neurosci 17, 1607-1612, 2014.

Russell J, Mahrabian A. Evidence for a Three-Factor Theory of Emotions. J Res Pers 11, 273-294, 1977.

Saavedra JM, Palkovits M, Brownstein MJ, Axelrod J. Serotonin distribution in the nuclei of the rat hypothalamus and preoptic region. Brain Res 77, 157-165, 1974. 
Sampaio KN, Mauad H, Biancardi VC, Barros JL, Amaral FT, Schenberg LC, Vasquez EC. Cardiovascular changes following acute and chronic chemical lesions of the dorsal periaqueductal gray in conscious rats. J Auton Nerv Syst 76, 99-107, 1999.

Satpute AB, Wager TD, Cohen-Adad J, Bianciardi M, Choi JK, Buhle JT, Wald LL, Barrett LF. Identification of discrete functional subregions of the human periaqueductal gray. Proc Natl Acad Sci U S A, 110, 17101-17106, 2013.

Schachter S, Singer JE. Cognitive, social, and physiological determinants of emotional state. Psychol Rev 69, 379-399, 1962.

Schenberg LC, Brandao CA, Vasquez EC. Role of periaqueductal gray matter in hypertension in spontaneously hypertensive rats. Hypertension 26, 1125-1128, 1995.

Sebe F, Aubin T, Boue A, Poindron P. Mother-young vocal communication and acoustic recognition promote preferential nursing in sheep. J Exp Biol 211, 3554-3562, 2008.

Shepherd SV, Freiwald WA. Functional networks for social communication in the Macaque Monkey. Neuron 99, 413-420, e3, 2018.

Sela VR, Biesdorf C, Ramos DH, Zangrossi H Jr, Graeff FG, Audi EA. Serotonin-1A receptors in the dorsal periaqueductal gray matter mediate the panicolytic-like effect of pindolol and paroxetine combination in the elevated T-maze. Neurosci Lett 495, 63-66, 2011.

Skultety FM. The behavioral effects of destructive lesions of the periaqueductal gray matter in adult cats. J Comp Neurol 110, 337-365, 1958.

Snider RS, Maiti A. Cerebellar contributions to the Papez circuit. J Neurosci Res 2, 133-146, 1976.

Stewart-Williams S, Podd J. The placebo effect: dissolving the expectancy versus conditioning debate. Psychol Bull $130,324-340,2004$.

Stone E, Coote JH, Allard J, Lovick TA. GABAergic control of micturition within the periaqueductal grey matter of the male rat. J Physiol 589, 2065-2078, 2011.

Subramanian HH, Balnave RJ, Holstege G. The midbrain periaqueductal gray control of respiration. J Neurosci 28, 12274-12283, 2008.

Sukikara MH, Mota-Ortiz SR, Baldo MV, Felicio LF, Canteras NS. The periaqueductal gray and its potential role in maternal behavior inhibition in response to predatory threats. Behav Brain Res 209, 226-233, 2010.

Swanson LW, McKellar S. The distribution of oxytocin- and neurophysin-stained fibers in the spinal cord of the rat and monkey. J Comp Neurol 188, 87-106, 1979.

Takasaki A, Hui M, Sasaki M. Is the periaqueductal gray an essential relay center for the micturition reflex pathway in the cat? Brain Res 1317, 108-115, 2010.

Tasker RR. Identification of pain processing systems by electrical stimulation of the brain. Hum Neurobiol 1, 261$272,1982$.

Teodorov E, Bernardi MM, Ferrari MF, Fior-Chadi DR, Felicio LF. Plasticity of opioid receptors in the female periaqueductal gray: multiparity-induced increase in the activity of genes encoding for mu and kappa receptors and a post-translational decrease in delta receptor expression. J Mol Neurosci 43, 175-181, 2011.

Turner EA. Cerebral control of respiration. Brain 77, 448-486, 1954.

van der Graaf M. In vivo magnetic resonance spectroscopy: basic methodology and clinical applications. Eur Biophys J 39, 527-540, 2010.

Veissier I, Boissy A. Stress and welfare: two complementary concepts that are intrinsically related to the animal's point of view. Physiol Behav 92, 429-433, 2007.

Vianna DML, Graeff FG, Landeira-Fernandez J, Brandao ML. Lesion of the ventral periaqueductal gray reduces conditioned fear but does not change freezing by stimulation of the dorsal periaqueductal gray. Learn Mem $8,164-169,2001$

Vianna DM, Brandao ML. Anatomical connections of the periaqueductal gray: specific neural substrates for different kinds of fear. Braz J Med Biol Res 36, 557-566, 2003.

Wager TD, Rilling JK, Smith EE, Sokolik A, Casey KL, Davidson RJ, Kosslyn SM, Rose RM, Cohen JD. Placeboinduced changes in FMRI in the anticipation and experience of pain. Science 303, 1162-1167, 2004.

Wager TD, van Ast VA, Hughes BL, Davidson ML, Lindquist MA, Ochsner KN. Brain mediators of cardiovascular responses to social threat, part II: Prefrontal-subcortical pathways and relationship with anxiety. Neuroimage 47, 836-851, 2009.

Walker P, Carrive P. Role of ventrolateral periaqueductal gray neurons in the behavioral and cardiovascular responses to contextual conditioned fear and poststress recovery. Neuroscience 116, 897-912, 2003.

Wiedenmayer CP, Barr GA. Mu opioid receptors in the ventrolateral periaqueductal gray mediate stress-induced analgesia but not immobility in rat pups. Behav Neurosci 114, 125-136, 2000. 
Wu D, Wang S, Stein JF, Aziz TZ, Green AL. Reciprocal interactions between the human thalamus and periaqueductal gray may be important for pain perception. Exp Brain Res 232, 527-534, 2014.

Xavier CH, Ianzer D, Lima AM, Marins FR, Pedrino GR, Vaz G, Menezes GB, Nalivaiko E, Fontes MA. Excitatory amino acid receptors mediate asymmetry and lateralization in the descending cardiovascular pathways from the dorsomedial hypothalamus. PLoS One 9, e112412, 2014.

Yoshida W, Seymour B, Koltzenburg M, Dolan RJ. Uncertainty increases pain: evidence for a novel mechanism of pain modulation involving the periaqueductal gray. J Neurosci 33, 5638-5646, 2013.

Yoshimura R, Kiyama H, Kimura T, Araki T, Maeno H, Tanizawa O, Tohyama M. Localization of oxytocin receptor messenger ribonucleic acid in the rat brain. Endocrinology 133, 1239-1246, 1993.

Young RF, Kroening R, Fulton W, Feldman RA, Chambi I. Electrical stimulation of the brain in treatment of chronic pain. Experience over 5 years. J Neurosurg 62, 389-396, 1985.

Young KS, Parsons CE, Stein A, Vuust P, Craske MG, Kringelbach ML. The neural basis of responsive caregiving behaviour: Investigating temporal dynamics within the parental brain. Behav Brain Res 325, 105-116, 2017.

Yu CX, Li B, Xu YK, Ji TT, Li L, Zhao CJ, Chen L, Zhuo ZZ. Altered functional connectivity of the periaqueductal gray in chronic neck and shoulder pain. Neuroreport 28, 720-725, 2017.

Zhang SP, Bandler R, Carrive P. Flight and immobility evoked by excitatory amino acid microinjection within distinct parts of the subtentorial midbrain periaqueductal gray of the cat. Brain Res 520, 73-82, 1990. 